\title{
Role of Hair Coverage and Sweating for Textile Friction on the Forearm
}

\author{
Jingchun Lyu ${ }^{1,2} \cdot$ Novaf Özgün $^{1} \cdot$ David J. Kondziela ${ }^{1,3} \cdot$ Roland Bennewitz $^{1,3}$
}

Received: 22 June 2020 / Accepted: 8 September 2020 / Published online: 19 September 2020

(c) The Author(s) 2020

\begin{abstract}
Friction of textiles on the human forearm is an important factor in comfort sensations of garments. We built an experiment to measure friction for textiles sliding on the forearm under loading conditions which are characteristic for wearing shirts or jackets. The hair coverage of the participants' forearm was quantified by image analysis of photographs of the arm in the region of contact. Friction results for five standard textiles suggest to treat hair coverage in two classes. Sweating after physical activity leads to an increase of friction by factors of 2 to 5 for participants with less hairy forearms, while an increase by a factor of 1 to 1.7 only was found for participants with more hairy forearms. We introduce a method of wetting the forearm of study participants in a controlled way with water, which results in similar friction as for the sweating forearm after physical activity. The method allows for efficient studies of the role of skin moisture for friction including varying hair coverage of the skin.
\end{abstract}

Keywords Skin friction $\cdot$ Textiles $\cdot$ Sweating $\cdot$ Hair $\cdot$ Comfort sensation

\section{Introduction}

Friction is generally believed to be a key ingredient in comfort sensations of textiles, as expressed in the wide-spread use of the friction parameter in the Kawabata evaluation system to analyze the handle of textiles [1-5]. The importance of low friction and the role of friction fluctuations in perceived pleasantness has been confirmed in a panel-base study for wide range of materials [6]. Hand friction was found to have strong negative correlation with comfort sensations for military garments [2]. Frictional properties of textiles were judged coherently by a panel as sticky-slippery attribute and showed a good correlation with overall comfort ratings [7]. It was shown that a friction experiment which is more sensitive to the textile's hairiness had better correlation with perceived comfort in a prickle test [8]. However, friction coefficients measured with commercial textile testing

Roland Bennewitz

roland.bennewitz@leibniz-inm.de

1 INM - Leibniz Institute for New Materials, Campus D2 2, 66123 Saarbrücken, Germany

2 Department of Materials Science and Engineering, Saarland University, 66123 Saarbrücken, Germany

3 Department of Physics, Saarland University, 66123 Saarbrücken, Germany systems depend on the probe shape and on the direction of sliding, and the relation between friction results of different testing systems is difficult to predict [9]. It is therefore important to measure textile friction on skin in a relevant geometry in studies motivated by comfort sensations.

When physical activity was included, discomfort as reported by a panel was shown to correlate to frictionrelated attributes such as stickiness and fabric cling for the sweat-wetted skin in contact with protective work wear [10]. Increased textile friction in high humidity led to a change in perceived texture and a correlated decrease in pleasantness [11]. A similar correlation of discomfort with stickiness sensations of fabrics was reported for participants during physical activity [12]. Closely related, the perception of wetness was also found to concur with stickiness perception when textiles were slid over the forearm [13]. The important role of frictional cues in wetness perception was confirmed by comparing static and dynamic tactile exploration of wet textiles [14]. Friction between skin and textiles increases by about a factor of two with increasing skin moisture or fabric wetness [11, 15-17].

We have not found systematic studies on textile friction on skin and the amount of hair coverage. Most friction studies are performed on glabrous skin, where the absence of hair reduces the complexity of interfacial interactions [18]. For metal friction versus skin at high load, friction was 
found to be lower at higher hair coverage, but this result was probably influenced by the different body locations tested [19]. One study found decreased friction for hair coverage as compared of chemically shaved skin for polypropylene sliding against the forearm at high load [20].

This overview of friction studies for dry and wet textiles indicates the importance of the topic for understanding the sensations arising from the sliding contact of textiles with skin. In our study we address two aspects which we believe need more attention. First, friction should be measured at the low apparent contact pressure which is characteristic for comfort sensations when wearing garments. Our benchmark is the pressure caused by the own weight of the textiles, which is given by the product of density $\left(100-250 \mathrm{~g} / \mathrm{m}^{2}\right.$ for a standard shirt) and gravitational constant $(9.81 \mathrm{~N} / \mathrm{kg})$ and is thus $1-2.5 \mathrm{~Pa}$ for a standard shirt, and still less than $10 \mathrm{~Pa}$ even if the weight of a sleeve hanging on the forearm is considered. Second, friction should be measured on the dorsal forearm which is the area on the upper body that eventually comes in to direct sliding contact with a large variety of different garments such as base layers, shirts, or jackets. Consequently, its hair coverage should be considered explicitly. We describe an experiment in which a stripe of textile, suspended at its two ends, is pulled over the dorsal forearm of participants with varying hair coverage. This experiment implements friction measurements at loads given by the textile's own weight and report results for five standard textiles and fifteen participants with varying hair coverage on the dorsal forearm. We introduce a method to apply wetness to the forearm in a controlled way which results in a similar change in friction compared to sweating after physical activity. With this study, we hope to contribute to an understanding of textile friction on the forearm, motivated by its key contribution to comfort sensation in the everyday and sportive use of garments.

\section{Experimental Procedures}

\subsection{Materials}

Five standard textiles were purchased at a local department store and used as received. Details on material, structure, and physical parameters are provided in Table 1. Scanning electron microscopy images of the fabric structure are provided in Fig. 1. The relative bending stiffness of the textiles was determined by the hanging loop method [21]. This method quantifies the stiffness by measuring the deformation of the fabric under its own weight in a heart-shaped geometry. The length of the hanging loop made from a textile stripe of $2 \times 20 \mathrm{~cm}^{2}$ is measured after 1 min waiting time, it is inversely related to the bending stiffness. The values vary by less than $30 \%$ for our textiles. Thickness of the fabrics was determined by optical microscopy.

\subsection{Quantification of Hair Coverage}

Digital photographs of the forearm of study participants were taken through a mask with an opening of $3 \times 3 \mathrm{~cm}^{2}$ (Fig. 2a). A ring-shaped lamp ensured illumination uniformity. The images were converted to binary images using the software ImageJ, with manual setting of the threshold to meet the contrast between hair and skin in each image (Fig. 2b). In cases of similar brightness of hair and skin, the color channels of the RGB image were separated and the red or green channel used for conversion to binary images. Hair coverage was quantified as the fraction of image pixels representing hair.

\subsection{Friction Experiments}

Stripes of $10 \times 42 \mathrm{~cm}^{2}$ were cut from the textiles and suspended from a stiff support beam of $36 \mathrm{~cm}$ length (see Fig. 2c). The beam was attached to a three-axis force sensor (ME Messsysteme (Hennigsdorf, Germany), model K3D40), which recorded normal and lateral forces up to $10 \mathrm{~N}$ with a data rate of $50 \mathrm{~Hz}$. The height of the support beam was adjusted such that it was at a distance of $1.5 \mathrm{~cm}$ from the posterior forearm of each participant. In this geometry, the textile is in contact with about one fifth of the circumference of the forearm. The normal force acting on the forearm was measured in stationary contact to be 25 to $40 \mathrm{mN}$ in proportion to the specific weight of the five textiles. This load corresponds to the weight of a piece of fabric of about $10 \times 16$ $\mathrm{cm}^{2}$ in agreement with our plan to measure friction under the weight of a sleeve. The typical contact area with the forearm
Table 1 Parameters for the five standard textiles investigated in this study: weave type, specific weight, length of a hanging loop as measure for bending compliance (see text), and fabric thickness

\begin{tabular}{lllllc}
\hline & Weave & Type & Weight $\left(\mathrm{g} / \mathrm{m}^{2}\right)$ & $\begin{array}{l}\text { Length of hanging } \\
\text { loop }(\mathrm{cm})\end{array}$ & Thickness $(\mu \mathrm{m})$ \\
\hline Cotton $(100 \%)$ & Twill & Woven & 195 & 7.1 & 427 \\
& Jersey & Knitted & 158 & 9.7 & 545 \\
& Plain & Woven & 146 & 7.8 & 415 \\
Polyester (100\%) & Jersey & Knitted & 267 & 8.1 & 1050 \\
& Plain & Woven & 173 & 6.9 & 409 \\
\hline
\end{tabular}



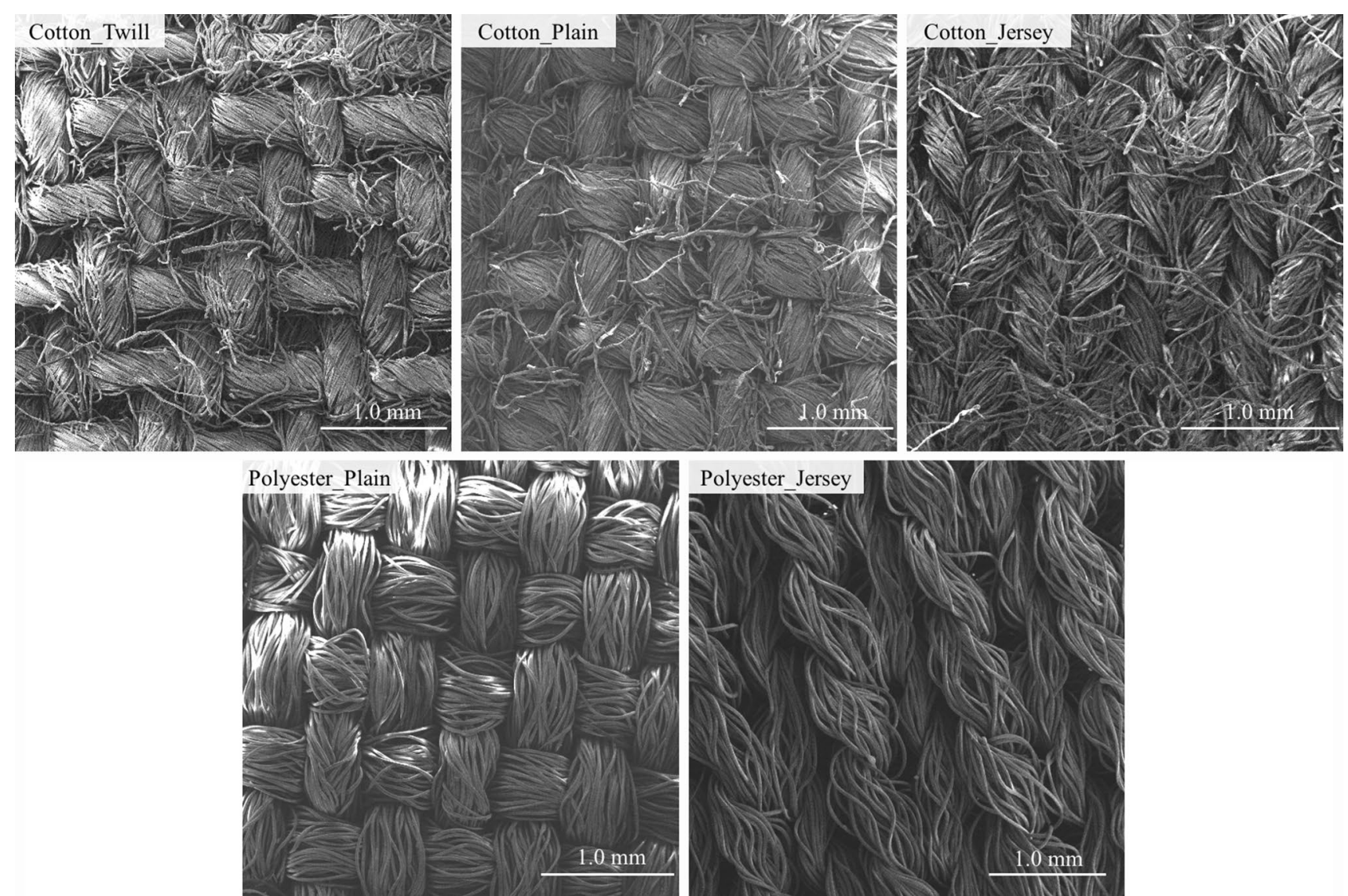

Fig. 1 Scanning electron microscopy of the five standard textiles investigated. The images were recorded with a FEI Quanta 400 ESEM
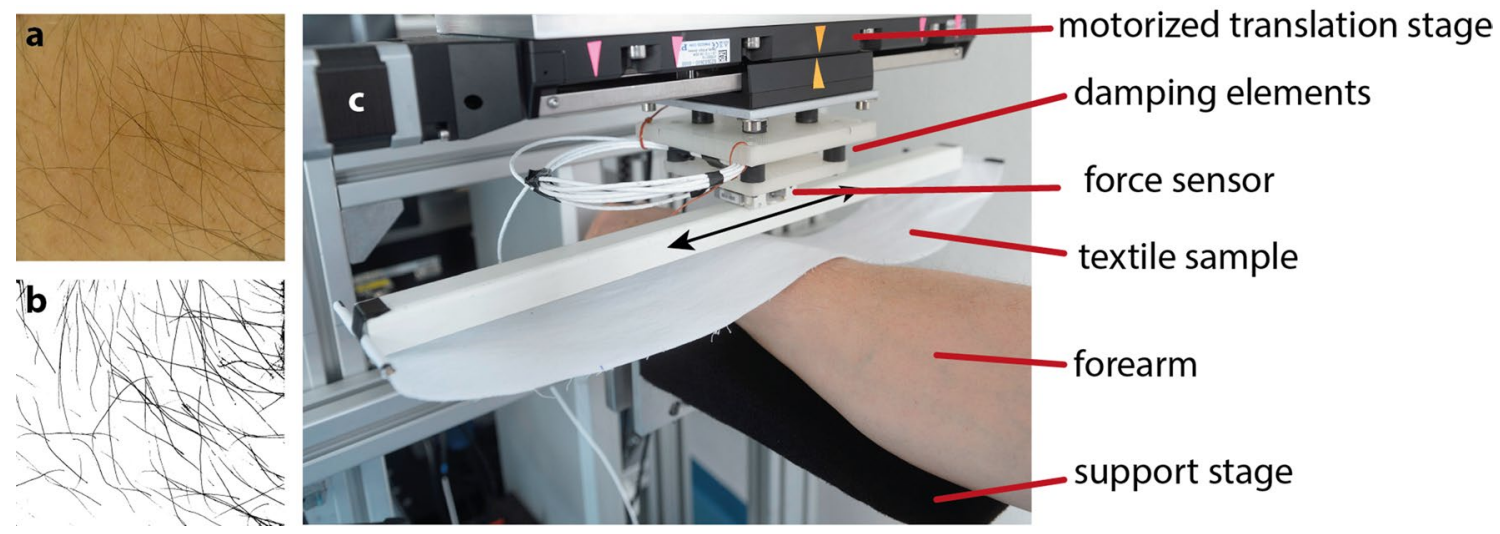

Fig. 2 a Digital photograph of the forearm of one participant in the contact area. b Binary version of the photograph, the fraction of black pixels of $6.3 \%$ is taken as the hair coverage. c Experimental setup for the measurement of sliding friction between textiles and the human forearm under conditions which are relevant for comfort sensations of garments. The support beam which carries the textile stripe is

was about $10 \times 8 \mathrm{~cm}^{2}$. The applied load, corresponding to an apparent contact pressure $<5 \mathrm{~Pa}$, is lower than in similar setups such as the body movement simulator by Tang et al. mounted to a three-axis force sensor. The force sensor is attached to a motorized translation stage via a damping stage by means of rubber posts, which reduce the transmission of vibrations from the translation stage to the force sensor. The forearm rests on a support. The height of the support beam with respect to the top of the arm is adjusted to be constant for each participant of the study

[22], the sliding experiment by Raccuglia et al. [13], or the quite similar setup by Kenins, where the applied pressure is still more than a factor of 20 higher [16]. Unfortunately, 
vibration noise of the motorized translation stage couples into the beam supporting the textile stripe and adds oscillatory noise to the normal force signal during sliding, so that contact-related deviations from its average value could not be measured as function of sliding time. Combining the desired geometry of the textile-skin contact and contact patches on the order of $100 \mathrm{~cm}^{2}$ with measurements of $\mathrm{mN}$ force fluctuations throughout the sliding cycle will require an optimized low-noise translation stage such as a parallelbeam construction with voice-coil drive [23].

Lateral forces were measured while the textile was sliding back and forth five times over a distance of $5 \mathrm{~cm}$ at a velocity of $20 \mathrm{~mm} / \mathrm{s}$, which is expected to provide a perception of pleasantness [24]. Average lateral forces were calculated as mean lateral force over all cycles, excluding times when the motorized translation stage was accelerating or decelerating at $50 \mathrm{~mm} / \mathrm{s}^{2}$ at the turning points. The sliding direction was parallel to the direction of weft. Please note that the lateral forces are measured parallel to the direction of pulling. We prefer to use the term lateral forces rather than friction forces, because friction forces should be measured parallel to the interface plane of the contact, which is not the case in our experiment's geometry. However, we believe that the measured lateral forces are the best possible measure for friction and its dependence on hair coverage and skin hydration. The laboratory was equipped with standard air condition with a room temperature between 20 and $21^{\circ} \mathrm{C}$ and a relative humidity between 40 and 50\%.

Study participants were volunteers working at the INMLeibniz Institute for New Materials or studying at Saarland University in the age group 23-30 years. The participants were informed about the goal of the study and the experimental procedure and explained that they could terminate their participation at any time without giving reason. No experiment deviated from everyday experience of contact with standard fabrics. Although no medical research was performed, the experiments were designed to follow the standards set by the Declaration of Helsinki. In particular, risk and burden for participants were minimized, no members of vulnerable groups and no participants with known health issues were included. Participants were not deceived about the goal of the study, no personal information other than age was collected, and no personal judgment asked. Participants gave their informed consent to the experiments.

\subsection{Wet and Sweating Forearm}

In order to reproducibly prepare a wet forearm for friction measurements, we applied a water-soaked disposable paper tissue to the arm. The tissue was made of $65 \%$ cellulose and $35 \%$ polyester and measured $19 \times 20.5 \mathrm{~cm}^{2}$ in size. It was placed on household cling foil and soaked by applying $25 \mathrm{ml}$ of distilled water, the largest amount which was fully absorbed by the tissue. The wet tissue was then placed on the forearm for 2 min together with the cling foil, which prevented evaporation of water. After 2 min, foil and tissue were removed and friction experiments commenced. The skin was visibly moist after the procedure, but had no water droplets on top at the time of the friction experiment.

In order to measure friction for the five textiles on sweating forearms, participants worked out on a stationary bike for $30 \mathrm{~min}$, after which time participants exhibited a glossy skin on the forearm due to sweating. We made sure that the heart rate did not exceed 120 per min at any time. We then measured friction for the first of the five fabrics. Participants reengaged in physical activity for 5 min while the sample was changed for the next fabric. This shorter exercise time was sufficient to again establish a sweat film on the skin of participants.

\section{Results and Discussion}

We quantified the hair coverage of the forearm of 15 participants as the fraction of pixels representing hair in digital photographs of the contact area. We found numbers ranging from 0 to $25 \%$. An overview of friction results recorded as a function of the hair coverage for the five different fabrics is given in Fig. 3. The lateral forces were recorded for each participant first on the dry forearm for all five textiles in the order of presentation in Fig. 3 .

In order to compare friction on dry and wet skin of the forearm, we introduced an easily reproducible method to apply water to the skin of the forearm. We soaked a disposable tissue with water, laid it on the arm and wrapped household cling foil over soaked tissue and arm for $2 \mathrm{~min}$. Tissue and foil were then removed and friction measurements resumed within $1 \mathrm{~min}$. For each participant, the five textiles were tested again in the same order. Directly before testing a new textile sample, the wetting procedure was repeated. The time lapse between wetting procedures was $10 \mathrm{~min}$.

We would like to draw the attention to the observation that friction findings for all fabrics in Fig. 3 were very similar for a hair coverage $<10 \%$ on the one hand and very similar for a hair coverage of $>10 \%$ on the other hand. We therefore discuss friction results for these two groups and refer to them as less hairy $(<10 \%)$ and more hairy $(>10 \%)$. A few observations on friction were made similarly for all fabrics. For less hairy participants, friction was significantly higher on the wet forearm than on the dry forearm ( $z$-value $>3$ for all participants and all textiles). The increase ranged from a factor of 1.2 to a factor of more than 4 for cotton plain and twill, from a factor of 2 to almost 10 for cotton jersey. The increase of friction on a wet forearm was less dramatic on polyester, from a factor of 1.1 up to a factor of 3 for plain and jersey. No such significant differences between wet and 

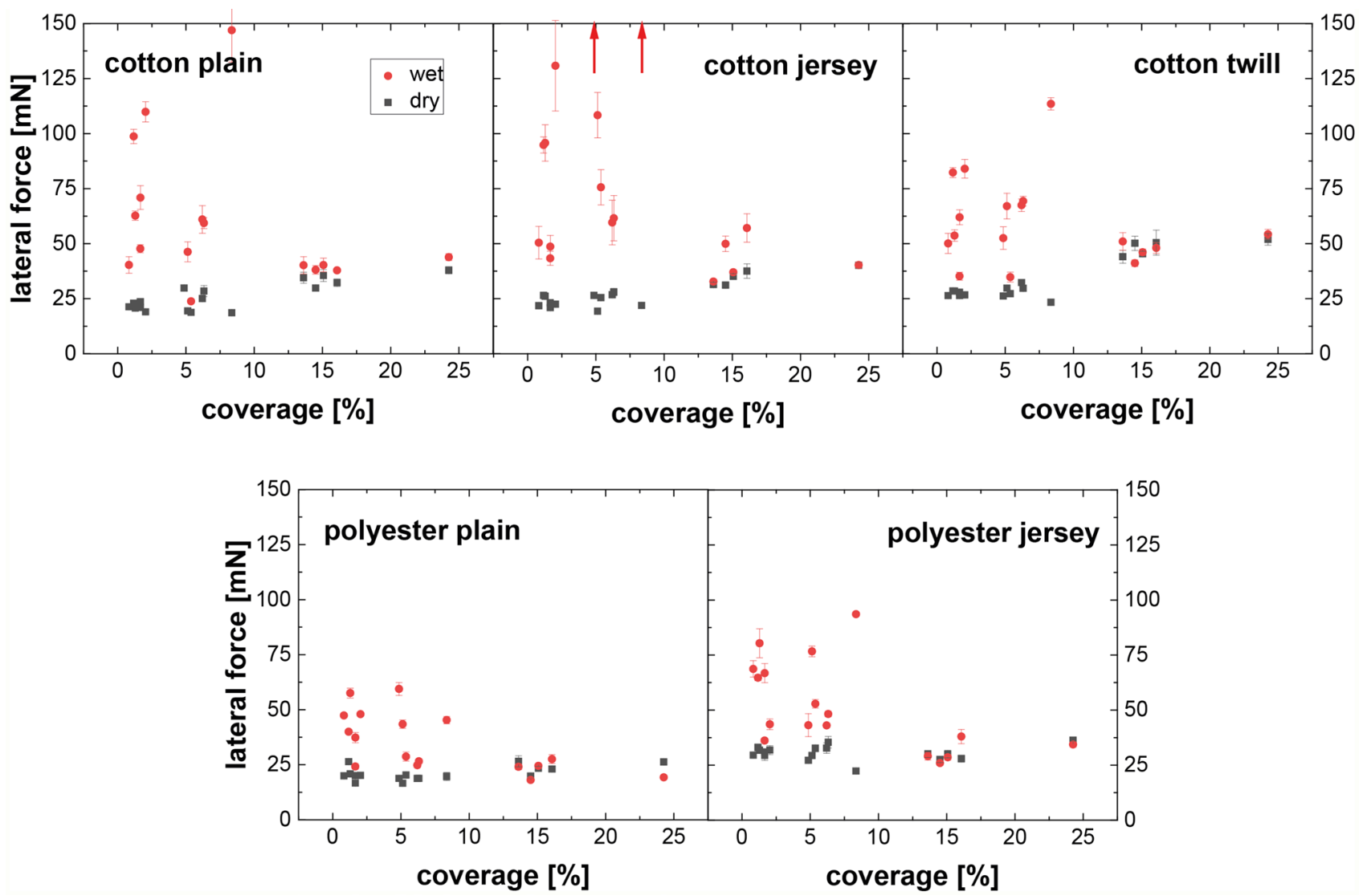

Fig. 3 Lateral force for five different standard textiles sliding over the wet or dry forearm of 15 participants, plotted as function of the hair coverage on the forearm. Lateral forces are averaged over five reciprocal sliding cycles of $5 \mathrm{~cm}$. Error bars represent the standard variation of lateral forces over the time of averaging. See text for the method of wetting the arm with water. Two red arrows indicate values higher than the scale of this graph $(4.9 \%-212 \mathrm{mN}, 8.5 \%-175 \mathrm{mN})$ dry skin were found for more hairy participants ( $z$-value $>3$ in only 3 cases, in 9 of 25 cases friction is actually lower for the wet forearm). The friction results for the wet forearm reveal large individual differences between participants with less hairy skin. We note that the standard deviation of lateral forces is smaller than the differences in average lateral force between participants. It can thus be excluded that the individual differences are result of a random sampling of large force fluctuation, caused for example by wet cling and strong stick-slip friction.
Table 2 and Fig. 4a summarize the friction results as averages over participants with less hairy and for participants with more hairy forearms. Friction forces for cotton fabrics in the dry case were lower on less hairy forearms (red open data points in Fig. 4) than on more hairy forearms $(z>2.2)$. We did not observe such difference in friction between hairy coverage for the polyester fabrics sliding on the dry forearm (differences less than standard variations). For the wet forearm, we did observe higher friction on less hairy arms for all textiles as described above. Friction results scattered
Table 2 Lateral force in $\mathrm{mN}$ averaged over less hairy and more hairy participants for the five textiles and comparing measurements on dry and wet forearm

\begin{tabular}{lccccc}
\hline & Cotton plain & Cotton jersey & Cotton twill & Polyester plain & Polyester jersey \\
\hline Less hairy & & & & & \\
Dry & $22.4 \pm 3.7(0.17)$ & $24.1 \pm 2.8(0.12)$ & $27.8 \pm 2.3(0.08)$ & $19.7 \pm 2.5(0.13)$ & $30.5 \pm 3.4(0.11)$ \\
Wet & $78 \pm 45(0.58)$ & $96 \pm 53(0.55)$ & $64 \pm 22(0.34)$ & $40 \pm 12(0.30)$ & $60 \pm 18(0.30)$ \\
More hairy & & & & & \\
Dry & $34.1 \pm 3.1(0.09)$ & $35.1 \pm 3.9(0.11)$ & $48.4 \pm 3.7(0.08)$ & $23.8 \pm 2.7(0.11)$ & $30.4 \pm 3.5(0.11)$ \\
Wet & $40.1 \pm 2.4(0.06)$ & $43.4 \pm 9.9(0.23)$ & $48.1 \pm 5.0(0.10)$ & $22.7 \pm 3.9(0.17)$ & $31.2 \pm 4.9(0.16)$ \\
\hline
\end{tabular}

Numbers in bracket are the coefficients of variation 


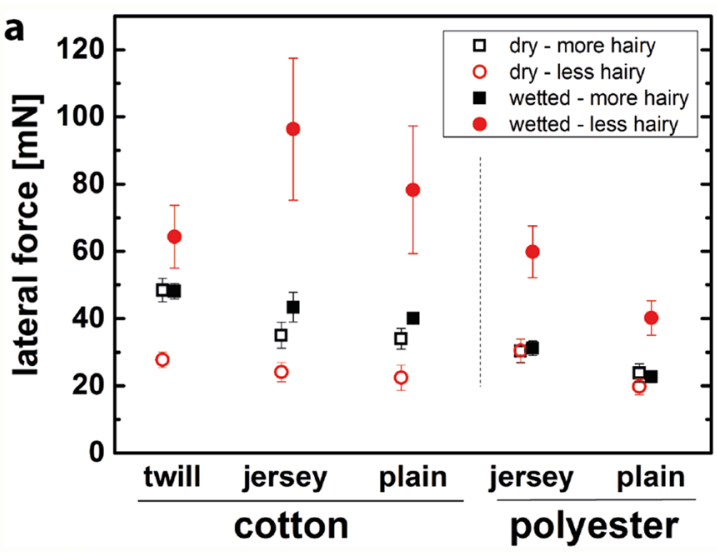

Fig. 4 a Comparison of average lateral forces for the five different standard textiles on dry and wet forearms, averaged for two groups of participants with less $(<10 \%$ coverage $)$ and $(>10 \%$ coverage $)$ more hairy forearms. Error bars represent the standard deviation of average friction values between participants. Cotton fabrics and polyes-

two to four times more for the wet forearm than for the dry case on less hairy arms, while on more hairy arms the scatter increased by only a factor of one to two (see coefficients of variation in Table 2). Our results indicate that individual relative differences in friction are largest for textiles sliding on less hairy wetted skin. Given the minor deformation of skin at the low loads in this experiment, we suggest that the scatter between participants reflects a variation of the effective adhesive shear stress between the textiles and the moist, plasticized skin. The effect of these differences is weakened by a hair coverage which lifts the direct contact.

The calculation of a friction coefficient requires the knowledge of lateral and normal forces at the interface. In the non-trivial geometry of our experiment, where the hanging stripes of fabric adapt to the curved shape of the forearm by their own weight, we can measure the overall lateral pulling force and the effective weight carried by the contact with the forearm. As described above, our confirmed estimate for the effective weight is that of a $10 \times 16 \mathrm{~cm}^{2}$ piece of textile. Taking into account the measured lateral force and the effective weight as approximation for the normal force, we estimated friction coefficients for the data in Fig. 4a and present them in Fig. 4b. While the analysis of the influence of hair coverage and wetness remains the same as in the analysis of lateral forces, the comparison of friction coefficients provides additional information about the role of materials. For friction on dry and less hairy arms, the coefficients of friction for cotton textiles are between 0.91 and 0.98 and for both polyester textiles are 0.73 . The differences between different structures (plain or jersey) are not significant with respect to the averages over participants $(z<1)$. For friction on dry and more hairy arms, the friction coefficients for cotton textiles are between 1.41 and 1.58 , for polyester 0.73

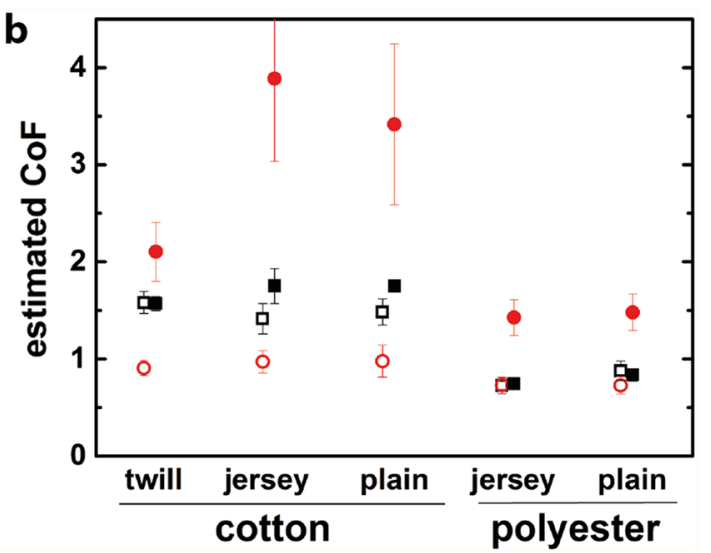

ter fabrics are ordered to decreasing specific weight, respectively. b Coefficient of friction estimated as ratio of lateral and normal force for the same dataset. The normal force is calculated as the weight of a $10 \times 16 \mathrm{~cm}^{2}$ piece of each textile (see text)

and 0.89. Again, differences in friction coefficients between different structures are not significant. We conclude that the friction coefficients on dry skin depend on the material and the hair coverage, but not on the weave structure. For friction on wet skin, only one difference between weave structures is significant, as in cotton twill has a smaller friction coefficient that plain and jersey $(z>2)$.

The findings on the relation of friction for wet and dry skin are summarized in Fig. 5a). A quotient between 1.0 and 1.3 for more hairy forearms was found for all materials, while factors between 2 and 4.5 were found for less hairy forearms. We wanted to know if our method of wetting the arms causes a friction increase which is comparable to the increase of friction on a sweating forearm after physical activity. Out of the 15 participants, 9 volunteered to work out on a stationary exercise bike and have friction measured on their sweating forearm. The results are summarized in Fig. 5b). For more hairy forearms, little increase in friction was found except for the plain cotton, for which friction increased on average by $70 \%$. For the less hairy forearms, the different materials exhibited the same order of increase in friction upon sweating as for the wetting case. A linear fit between the data points in Fig. 5a and b results in a slope of 0.79 . The wetting method thus slightly underestimates the friction increase due to sweating, however, with a strong linear correlation between friction results $\left(R^{2}=0.972\right.$, Pearson rank order coefficient 0.987 ).

In order to understand how well the wetting method can predict friction individually for the sweating arm, we plot the lateral force values for sweating versus wet arm in Fig. 6 . Ideally, all values should lie on a straight line with slope 1 . We fitted the data for all five materials and each participant to the equation $F_{\text {lateral }}^{\text {sweating }}=m \cdot F_{\text {lateral }}^{\text {wet }}$ and present the 

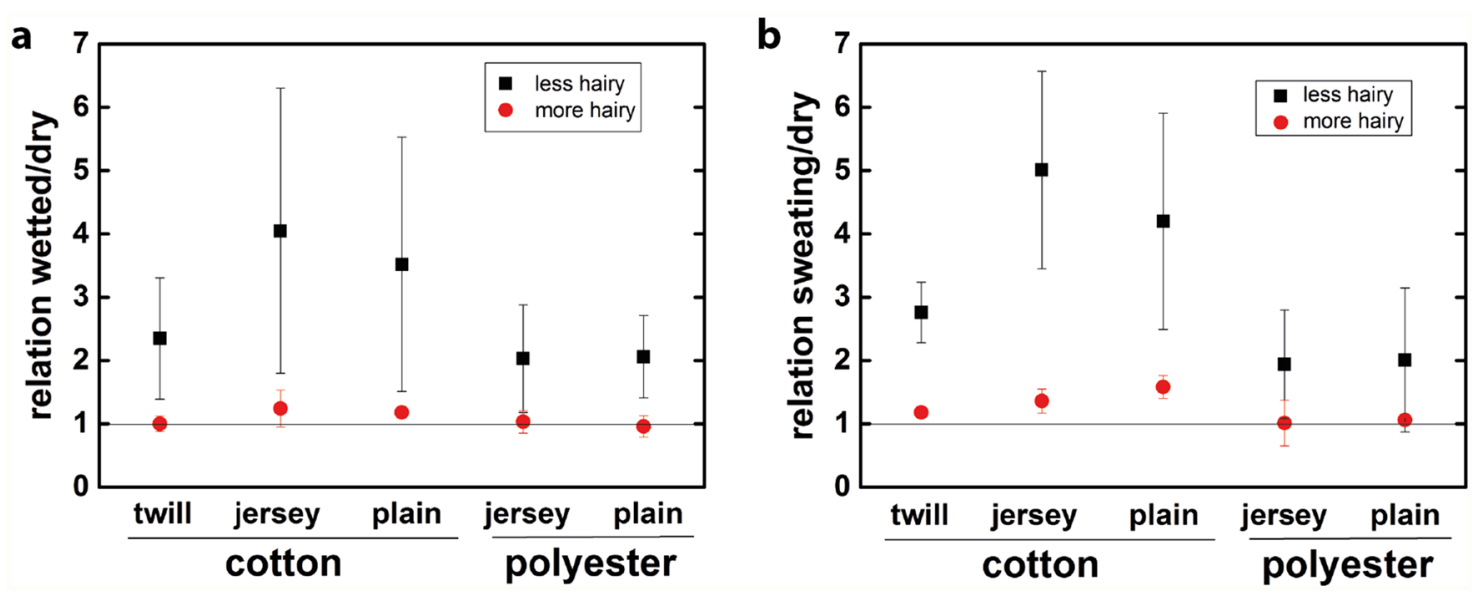

Fig. 5 Relation of average lateral forces for the five different standard textiles between a wet and dry forearms and $\mathbf{b}$ sweating and dry forearm. The data are averaged for two groups of participants with less $(<10 \%$ coverage $)$ and $(>10 \%$ coverage $)$ more hairy forearms

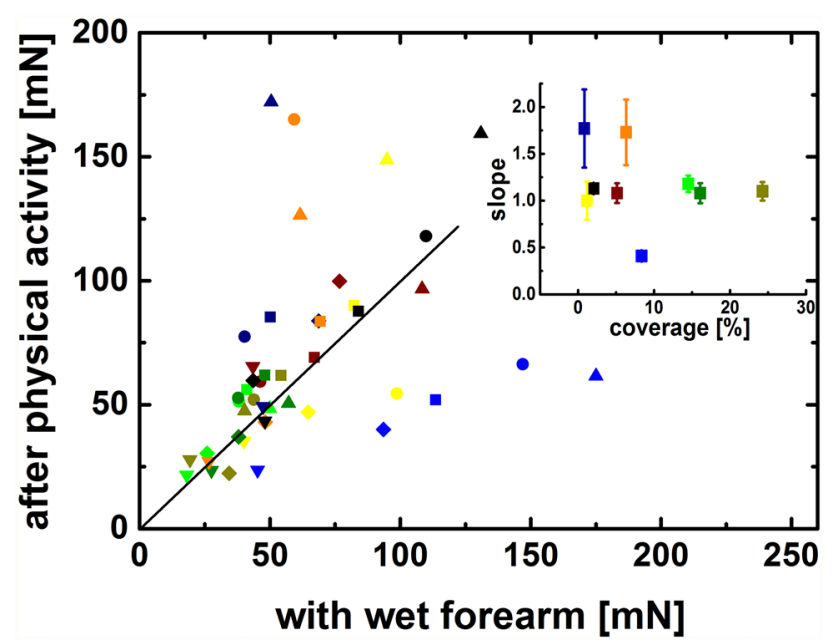

Fig. 6 Average lateral force recorded on the sweating forearm plotted versus average lateral force measured on the wet forearm. Color of data points represents the different participants, the symbol the respective fabric (filled square cotton twill, filled circle cotton plain, filled triangle cotton jersey, filled inverted triangle polyester plain, filled diamond polyester jersey). The insert reports the slope for each participants with fitting error represented by error bars

resulting slope $m$ as function of the hair coverage in the insert of Fig. 6. The value is between 1.0 and 1.2 for six out of nine participants, indicating the potential of the wetting method as predictive tool for friction on sweating forearms. Friction after physical activity is up to $20 \%$ higher than after wetting the arm with water. One participant exhibited lateral force values which were a factor of two lower in sweating compared to the wet arm for all fabrics, probably due to the observed low degree of sweating. Two less hairy participants exhibited stronger lateral forces indicating cling after physical activity, probably due sweat droplets observed on their arms. Since our design of the physical activity study was based on constant exercise time and a limit in heart rate increase, different participants could be expected to show different degree of sweating. However, when the sweating was strong enough to fully moisturize the skin but not as strong as producing droplets on the skin, correlation between friction increase on wetted and on sweating arm was strong across the five textiles. The experiments for sweating forearms were designed to have comparable skins conditions for the friction tests of all five textiles, by a long initial physical activity $(30 \mathrm{~min})$ to establish a steady state of sweating skin and then by intermittent physical activity ( $5 \mathrm{~min}$ ) between friction tests to maintain this steady state. It is a limitation of this method that we cannot fully exclude changes of the skin hydration while testing the five textiles in each participant.

The dependence of friction on hair coverage has to be discussed in terms of the actual contact formation between textiles and forearm. On more hairy forearms, i.e., where digitized photographs revealed a hair coverage $>10 \%$, the textiles are in contact with the hair only. This observation was made in close-up movies recorded along the dorsal forearm. Even for the wetted or sweating forearm, where the hair tends to attach to the skin, it still prevents direct contact between skin and textiles at the low loads realized in this study. For polyester textiles, dry friction is very similar for less and more hairy forearms, while for cotton textiles friction is higher on more hairy arms. We attribute this increase in friction to an entanglement of skin hair with loose fiber ends of the cotton textiles (cf. Fig. 1). Hairiness of the textiles has been shown before to be an important factor for friction [25-27]. The friction coefficients which we estimated from the ratio of measured lateral force and textile weight are a higher than those reported in literature $[15,28,29]$. However, the comparison of friction coefficients is difficult for friction values recorded at very low applied loads, when adhesive contributions to normal forces 
lead to deviations from Amontons' Law. In this case, the real area of contact is no linear function of applied load with zero intercept anymore [17].

The increase of friction on less hairy forearms upon wetting or sweating by a factor of two and more is in agreement with previous reports. The increase of friction on wet skin has mostly been attributed to the swelling and softening of the skin and the subsequent increase in real area of contact with the counter body [30]. Gerhardt et al. found that friction of hospital textiles increases with skin hydration of the inner forearm by a factor of up to two [15]. Gwosdow et al. reported an increase of friction coefficients by a factor of two for sweat-covered skin, but no difference between textiles such as burlap, linen, wool, or cotton [11]. Kenins found that wetness increases friction by a factor of two, again rather independent of whether wool, cotton, or polyester was sliding on the forearm [16]. Our results on friction increase on wet skin, recorded at much lower load than the ones summarized above, suggest to distinguish between lower and higher hair coverage. Higher hair coverage effectively prevents direct contact between textile and wet skin, resulting in less friction increase than the factor of two reported in most studies. Friction on less hairy forearms increases by a factor of two (polyester) and larger (cotton), confirming the strong dependence of interfacial shear stress between skin and textile on the skin hydration. For the low-load conditions in our experiments, we find a material contrast, namely a larger increase for cotton than for polyester for both wetting and sweating, and for plain woven and jersey knitted fabrics. We suggest that the hydrophilicity of cotton contributes to particularly large increase in friction by a factor of four on wet skin. A plausible mechanism suggested by Tang et al. invokes the formation of an adhesive interface when water transfers from the wet arm to the hydrophilic cotton, while a water-film repelled from the hydrophobic polyester may act as lubricant [31]. We propose that these skin-textile interface effects, whose relative contribution becomes stronger when the external load is very low, lead to the observed strong increase in friction and eventually to a reduced comfort of garments worn during physical exercise. The interface effects are attenuated by hair coverage larger than $10 \%$, when direct contact between skin and textiles is more and more blocked.

\section{Conclusions}

An experimental method was introduced for measuring friction between textiles and the dorsal forearm at the very low loads $(<5 \mathrm{~Pa})$ relevant for comfort sensations while wearing garments. Stronger hair coverage, quantified by image analysis, led to higher dry friction with cotton but not with polyester. The increase in friction on sweating or wet skin affects mostly less hairy arms, it is higher for cotton than for polyester. We introduce and validate a method of reproducibly wetting the arm by pure water which has the potential to predict friction of a sweating arm without need for tedious studies involving physical activity of participants [10]. The method opens opportunities for future work where textile structure, material, and surface chemistry are varied independently to reveal mechanisms underlying the differences in friction response between fabrics as observed in this study.

Acknowledgements We thank Günther Schlee of W. L. Gore \& Associates $\mathrm{GmbH}$ for suggesting the problem, advice in designing the study, and for instructive discussions of the results.

Funding Open Access funding enabled and organized by Projekt DEAL. The experiments described in this manuscript were not supported by any third-party funding.

Data Availability Experimental data are available from the corresponding author at reasonable request.

\section{Compliance with Ethical Standards}

Conflict of interest The authors declare no competing interests.

Open Access This article is licensed under a Creative Commons Attribution 4.0 International License, which permits use, sharing, adaptation, distribution and reproduction in any medium or format, as long as you give appropriate credit to the original author(s) and the source, provide a link to the Creative Commons licence, and indicate if changes were made. The images or other third party material in this article are included in the article's Creative Commons licence, unless indicated otherwise in a credit line to the material. If material is not included in the article's Creative Commons licence and your intended use is not permitted by statutory regulation or exceeds the permitted use, you will need to obtain permission directly from the copyright holder. To view a copy of this licence, visit http://creativecommons.org/licenses/by/4.0/.

\section{References}

1. Atalie, D., Gideon, R.K., Ferede, A., Tesinova, P., Lenfeldova, I.: Tactile comfort and low-stress mechanical properties of halfbleached knitted fabrics made from cotton yarns with different parameters. J. Nat. Fibers (2019). https://doi.org/10.1080/15440 478.2019.1697989

2. Cardello, A.V., Winterhalter, C., Schutz, H.G.: Predicting the handle and comfort of military clothing fabrics from sensory and instrumental data: development and application of new psychophysical methods. Text. Res. J. 73(3), 221-237 (2003). https://doi. org/10.1177/004051750307300306

3. Behera, B.K., Ishtiaque, S.M., Chand, S.: Comfort properties of fabrics woven from ring-, rotor-, and friction-spun yarns. J. Text. Inst. 88(3), 255-264 (1997). https://doi.org/10.1080/0040500970 8658549

4. Kawabata, S., Niwa, M., Yamashita, Y.: Recent developments in the evaluation technology of fiber and textiles: toward the engineered design of textile performance. J. Appl. Polym. Sci. 83(3), 687-702 (2002). https://doi.org/10.1002/app.2264 
5. Nayak, R.K., Punj, S.K., Chatterjee, K.N., Behera, B.K.: Comfort properties of suiting fabrics. Indian J. Fibre Text. Tes. 34(2), 122-128 (2009)

6. Klöcker, A., Wiertlewski, M., Theate, V., Hayward, V., Thonnard, J.L.: Physical factors influencing pleasant touch during tactile exploration. PLoS ONE 8(11), e79085 (2013). https://doi. org/10.1371/journal.pone.0079085

7. Tadesse, M.G., Harpa, R., Chen, Y., Wang, L., Nierstrasz, V., Loghin, C.: Assessing the comfort of functional fabrics for smart clothing using subjective evaluation. J. Ind. Text. 48(8), 1310 1326 (2019). https://doi.org/10.1177/1528083718764906

8. Bertaux, E., Lewandowski, M., Derler, S.: Relationship between friction and tactile properties for woven and knitted fabrics. Text. Res. J. 77(6), 387-396 (2007). https://doi.org/10.1177/00405 17507074165

9. Capdevila, F.X., Carrera-Gallissa, E., Escusa, M., Rotela, M.: Canonical analysis of the Kawabata and sliding fabric friction measurement methods. J. Text. Inst. (2020). https://doi. org/10.1080/00405000.2019.1670924

10. Yoo, S., Barker, R.L.: Comfort properties of heat resistant protective workwear in varying conditions of physical activity and environment Part II perceived comfort response to garments and its relationship to fabric properties. Text. Res. J. 75(7), 531-539 (2005). https://doi.org/10.1177/0040517505054190

11. Gwosdow, A.R., Stevens, J.C., Berglund, L.G., Stolwijk, J.A.J.: Skin friction and fabric sensations in neutral and warm environments. Text. Res. J. 56(9), 574-580 (1986). https://doi. org/10.1177/004051758605600909

12. Raccuglia, M., Sales, B., Heyde, C., Havenith, G., Hodder, S.: Clothing comfort during physical exercise-determining the critical factors. Appl. Ergonomics 73, 33-41 (2018). https://doi. org/10.1016/j.apergo.2018.05.014

13. Raccuglia, M., Pistak, K., Heyde, C., Qu, J.G., Mao, N.T., Hodder, S., Havenith, G.: Human wetness perception of fabrics under dynamic skin contact. Text. Res. J. 88(19), 2155-2168 (2018). https://doi.org/10.1177/0040517517716905

14. Tiest, W.M.B., Kosters, N.D., Kappers, A.M.L., Daanen, H.A.M.: Phase change materials and the perception of wetness. Ergonomics 55(4), 508-512 (2012). https://doi.org/10.1080/00140 139.2011.645886

15. Gerhardt, L.C., Strassle, V., Lenz, A., Spencer, N.D., Derler, S.: Influence of epidermal hydration on the friction of human skin against textiles. J. R. Soc. Interface 5(28), 1317-1328 (2008). https://doi.org/10.1098/rsif.2008.0034

16. Kenins, P.: Influence of fiber-type and moisture on measured fabric-to-skin friction. Text. Res. J. 64(12), 722-728 (1994). https:// doi.org/10.1177/004051759406401204

17. Comaish, S., Bottoms, E.V.A.: The skin and friction: deviations from amonton's laws, and the effects of hydration and lubrication. Br. J. Dermatol. 84(1), 37-43 (1971). https://doi. org/10.1111/j.1365-2133.1971.tb14194.x

18. Derler, S., Gerhardt, L.C.: Tribology of skin: review and analysis of experimental results for the friction coefficient of human skin.
Tribol. Lett. 45(1), 1-27 (2012). https://doi.org/10.1007/s1124 9-011-9854-y

19. Veijgen, N.K., Masen, M.A., van der Heide, E.: Variables influencing the frictional behaviour of in vivo human skin. J. Mech. Behav. Biomed. Mater. 28, 448-461 (2013). https://doi.org/10.1016/j. jmbbm.2013.02.009

20. Ramirez, J.F., Pavon, J.J., Toro, A.: Experimental assessment of friction coefficient between polypropylene and human skin using instrumented sclerometer. Proc. Inst. Mech. Eng. Part J 229(3), 259-265 (2015). https://doi.org/10.1177/1350650114526579

21. Peirce, F.T.: 26-the "handle" of cloth as a measurable quantity. J. Text. Inst. Trans. 21(9), T377-T416 (1930). https://doi. org/10.1080/19447023008661529

22. Tang, K.-P.M., Chau, K.-H., Kan, C.-W., Fan, J.-T.: Magnitude estimation approach for assessing stickiness sensation perceived in wet fabrics. Fibers Polym. 19(11), 2418-2430 (2018). https:// doi.org/10.1007/s12221-018-8626-9

23. Fagiani, R., Massi, F., Chatelet, E., Berthier, Y., Akay, A.: Tactile perception by friction induced vibrations. Tribol. Int. 44(10), 1100-1110 (2011). https://doi.org/10.1016/j.triboint.2011.03.019

24. Ackerley, R., Carlsson, I., Wester, H., Olausson, H., Backlund Wasling, H.: Touch perceptions across skin sites: differences between sensitivity, direction discrimination and pleasantness. Front. Behav. Neurosci. 8, 54-54 (2014). https://doi.org/10.3389/ fnbeh.2014.00054

25. Kilic, G.B., Okur, A.: Effect of yarn characteristics on surface properties of knitted fabrics. Text. Res. J. 89(12), 2476-2489 (2019). https://doi.org/10.1177/0040517518797337

26. Camillieri, B., Bueno, M.A.: Indentation of hairy surfaces: role of friction and entanglement. Tribol. Int. 83, 120-129 (2015). https ://doi.org/10.1016/j.triboint.2014.11.009

27. Bueno, M.A., Bocquet, R., Tourlonias, M., Rossi, R.M., Derler, S.: Study of friction mechanisms of hairy textile fabrics. Wear 303(12), 343-353 (2013). https://doi.org/10.1016/j.wear.2013.03.035

28. Vilhena, L., Ramalho, A.: Friction of human skin against different fabrics for medical use. Lubricants (2016). https://doi. org/10.3390/lubricants4010006

29. Darden, M.A., Schwartz, C.J.: Investigation of skin tribology and its effects on the tactile attributes of polymer fabrics. Wear 267(58), 1289-1294 (2009). https://doi.org/10.1016/j.wear.2008.12.041

30. Adams, M.J., Briscoe, B.J., Johnson, S.A.: Friction and lubrication of human skin. Tribol. Lett. 26(3), 239-253 (2007). https://doi. org/10.1007/s11249-007-9206-0

31. Tang, K.P.M., Kan, C.W., Fan, J.T.: Psychophysical measurement of wet and clingy sensation of fabrics by the volar forearm test. J. Sens. Stud. 30(4), 329-347 (2015). https://doi.org/10.1111/ joss.12161

Publisher's Note Springer Nature remains neutral with regard to jurisdictional claims in published maps and institutional affiliations. 